\title{
Raster-scanned carbon ion therapy for malignant salivary gland tumors: acute toxicity and initial treatment response
}

\author{
Alexandra D Jensen ${ }^{1 *}$, Anna V Nikoghosyan', Swantje Ecker ${ }^{2}$, Malte Ellerbrock², Jürgen Debus ${ }^{1}$, Klaus K Herfarth \\ and Marc W Münter ${ }^{1}$
}

\begin{abstract}
Background and purpose: To investigate toxicity and efficacy in high-risk malignant salivary gland tumors (MSGT) of the head and neck. Local control in R2-resected adenoid cystic carcinoma was already improved with a combination of IMRT and carbon ion boost at only mild side-effects, hence this treatment was also offered to patients with MSGT and microscopic residual disease (R1) or perineural spread (Pn+).

Methods: From November 2009, all patients with MSGT treated with carbon ion therapy were evaluated. Acute side effects were scored according to CTCAE v.4.03. Tumor response was assessed according to RECIST where applicable.

Results: 103 patients were treated from 11/2009 to 03/2011, median follow-up is 6 months. 60 pts received treatment following R2 resections or as definitive radiation, 43 patients received adjuvant radiation for R1 and/or $\mathrm{Pn}+16$ patients received carbon ion treatment for re-irradiation. Median total dose was 73.2 GyE (23.9 GyE carbon ions + 49,9 Gy IMRT) for primary treatment and $44.9 \mathrm{GyE}$ carbon ions for re-irradiation. All treatments were completed as planned and generally well tolerated with no $>$ CTC ${ }^{\circ}$ II toxicity. Rates of CTC ${ }^{\circ} \mid l$ toxicity (mucositis and dysphagia) were $8.7 \%$ with side-effects almost completely resolved at first follow-up.

47 patients showed good treatment responses (CR/PR) according to RECIST.

Conclusion: Acute toxicity remains low in IMRT with carbon ion boost also in R1-resected patients and patients undergoing re-irradiation. R2-resected patients showed high rates of treatment response, though follow-up is too short to assess long-term disease control.
\end{abstract}

\section{Introduction}

Malignant salivary gland tumors (MSGT) are rare and account for about $3-5 \%$ of head and neck cancers. They include a heterogeneous group of various histological subtypes with high-grade tumors such as mucoepidermoid carcinoma and adenoid cystic carcinoma (ACC) [1]. MSGTs are generally characterized by a rather slow pattern of growth, perineural spread and high propensity for hematogenous metastases, therefore outcome is still hampered by the incidence of distant metastases. Standard therapy of localized high-grade MSGT consists of

\footnotetext{
* Correspondence: Alexandra.Jensen@med.uni-heidelberg.de 'Dept. Radiation Oncology, University of Heidelberg, INF 400, 69120 Heidelberg, Germany

Full list of author information is available at the end of the article
}

complete surgical resection and adjuvant radiation in high-risk situations $(\mathrm{R}+$ or close margin, perineural spread, large tumors (T3/4), or nodal metastases) [2-4]. Radiation doses of $>60$ Gy or even 66 Gy are recommended to achieve local control [5-7].

Local control in MSGT was significantly improved by high-precision radiotherapy techniques, dose-escalation and high-LET radiation [8-12].

Intensity-modulated radiation therapy (IMRT) as well as fractionated stereotactic RT could already improve local control as compared to conventional RT techniques achieving 3-year PFS rates of $38 \%$ even in large ACCs [13].

The highest local control rates at $75-100 \%[10,12]$ are achieved by neutron radiation albeit at the cost of

\section{Biomed Central}

(c) 2011 Jensen et al; licensee BioMed Central Ltd. This is an Open Access article distributed under the terms of the Creative Commons Attribution License (http://creativecommons.org/licenses/by/2.0), which permits unrestricted use, distribution, and reproduction in any medium, provided the original work is properly cited. 
significant late toxicity. Heavy ion therapy using carbon ions however, showed a mild toxicity profile, no $\mathrm{CTC}^{\circ} \mathrm{III}$ late toxicities and very few ${ }^{\circ} \mathrm{III}$ acute reactions were observed [11]. Proton radiotherapy yielded an overall local control of $93 \%$ at 5 years; however, the authors noted several ${ }^{\circ} \mathrm{III}$ as well as one ${ }^{\circ} \mathrm{V}$ late toxicity (temporal lobe necrosis) [14]. A retrospective analysis of patients treated with neutrons reported slightly disappointing local control rates of $57 \%$ at 5 years accompanied with significant late toxicity $\left(14 \%>\right.$ CTC $\left.{ }^{\circ} \mathrm{III}\right)$ [10]. IMRT plus carbon ion boost for ACC showed very favorable results without the dreaded late toxicity resulting in local control rates of $78 \%$ at 4 years [9]. These results in turn led to the acceptance of this regimen as the standard treatment for ACC in Germany. A recent update of patients with ACC treated with this regimen between 1997 and 2008 confirmed initial results with consistently low treatment-related side effects $[9,15,16]$.

Charged-particle therapy promises improved results for all types of malignant salivary gland cancers. We would like to report early toxicity in a patient cohort including various R1-resected and re-irradiated MSGT of the head and neck.

\section{Patients and methods}

103 patients were treated with raster-scanned carbon ion therapy from November 2009 to March 2011. Toxicity was assessed at completion of treatment and on each follow-up visit. Treatment response was evaluated according to RECIST based on contrast-enhanced MRIscans where applicable.

\section{Patients}

Patients with histologically confirmed or surgically removed malignant tumors of the salivary glands (head and neck) were offered combined IMRT plus C12-boost in cases where tumors were either surgically inoperable or partially (R2) resected. In contrast to our initial experience [9], also patients with microscopic residues (R1) or perineural invasion $(\mathrm{Pn}+)$ were offered the combination regimen. Prior RT was not an exclusion criterion if another course of radiation therapy was justifiable.

\section{Radiotherapy}

\section{Immobilization/planning examinations}

Patients were immobilized with scotch cast or thermoplastic head masks with shoulder fixation. Planning examinations consisted of CT and contrast-enhanced MRI for 3D image correlation.

\section{Target volumes/dose prescription}

Primary treatment CTV1 (carbon ion boost) includes the macroscopic tumor/prior tumor bed, CTV 2 typical pathways of spread/ipsilateral nodal levels (II/III), further levels are included as indicated details of target volume definition are described in our current standard protocol [17].

We prescribed a dose of $24 \mathrm{GyE}$ carbon ions to the CTV1 (coverage: 95\% prescription isodose). CTV2 receives 50 Gy IMRT (coverage > 90\% of prescription isodose).

Re-irradiation Patients undergoing re-irradiation receive carbon ion therapy alone; CTV1 is limited to the visible tumor only. Doses are prescribed highly individually depending on prior RT and interval between the two treatments.

\section{Treatment and patient position control}

Carbon ions Carbon ion therapy is given in active beam application in the raster-scanning method [18] at the Heidelberg Ion Beam Therapy Centre (HIT). Inverse treatment planning is carried out on a dedicated planning system (Siemens TPS $^{\circledR}$ ) including biological RT optimization tools. Intensity-modulated particle therapy (IMPT) and single-beam optimization (SBO) techniques are used for plan generation in MSGTs.

Treatment is given at $3 \mathrm{GyE}$ per fraction ( $5 \mathrm{x} /$ week), daily image guidance consists of orthogonal $x$-rays in treatment position. An automatic 2D-3D pre-match is carried out (Siemens syngo PT treatment) and verified and manually adjusted online by the radiotherapist based on bony anatomy. Shifts were always corrected using a robotic table in six degrees of freedom.

IMRT IMRT is given in 25 fractions ( $5 \mathrm{x} /$ week) after inverse planning with the optimization tool KonRad $\operatorname{MRC}^{\circledR}$ (Siemens OCS) on a $6 \mathrm{MV}$ linear accelerator in step-and-shoot technique or on a $6 \mathrm{MV}$ tomotherapy unit.

Regular image guidance is carried out as MV conebeam CT or MV portal images. Total doses include doses by daily image guidance with MV CT.

\section{Treatment schedule/follow-up}

Most patients received upfront carbon ion boost followed by IMRT corresponding to a total dose of approximately 74 GyE (total treatment duration: approximately 7 weeks).

First follow-up including fibreoptic examination and MRI is carried out 6 weeks post completion of RT. Further MRI controls follow 3, 6, and 12 months thereafter, in 6 monthly intervals until 2 years post RT, then in yearly intervals.

\section{Analysis}

Evaluation of toxicity was carried out according to NCI CTCAE v.4.03, treatment was evaluated using the RECIST-criteria if applicable (R2-resected or inoperable tumors) [19].

\section{Results}

Treatment has been completed in 103 patients. Median age in our cohort is 56 years, median follow-up 6 
months. Diagnostic images of the first follow- are available in 90 patients. Two patients from abroad are lost to follow-up.

Sixty patients had a visible residual tumour or had not undergone prior surgery (group 1), 43 patients had undergone $\mathrm{R}+$ resections and/or showed extensive perineural spread $(\mathrm{Pn}+)$ (group 2). Eight out of 43 patients (group 1) and 26/60 patients (group 2) were treated for local relapse following initial surgery. Eighty-seven patients received treatment as part of their primary therapy. Sixteen patients received carbon ion therapy as reirradiation.

The majority of patients was treated for ACC and advanced tumor stages (table 1).

All except 3 patients received radiation only, one patient with extensive ACC received cetuximab weekly in addition, two patients with squamous cell carcinoma cisplatin $40 \mathrm{mg} / \mathrm{m}^{2}$ body surface weekly throughout therapy ( 1 patient as primary therapy, 1 patient for reirradiation).

\section{Primary treatment}

Median target volumes ( $\mathrm{n}=87 \mathrm{pts}$ ) were $368 \mathrm{ml}$ (IMRT; CTV2) and $128.6 \mathrm{ml}$ (carbon ion boost; CTV1), median total dose was $73.2 \mathrm{~Gy}$. Ten patients with tumors close to or crossing midline received bilateral cervical irradiation, for three patients with positive cervical lymph nodes and perinodal infiltration, our standard dose prescription was changed to 54 - 56 Gy to the CTV2 and 18 GyE C12.

Seventeen carbon ion plans needed to be optimized as IMPT, carbon ion treatment was mostly applied over 2 non-coplanar beams (table 2).

\section{Re-irradiation}

Sixteen patients received carbon ion therapy for re-irradiation of recurrent disease at the former field edge (2 pts), within the dose gradient to the optic nerve (2 pts), and in-field (12 pts). Median interval between the two RT courses was 66 months, median prior radiation dose 70 Gy. Six patients had initially received 72 GyE as combined treatment with carbon ion boost. Median re-treatment dose was $44.9 \mathrm{GyE}$ (table 2).

One patient had initially received electrons to a small parotid field $>20$ years ago, therefore this patient also received the standard IMRT + C12-boost concept despite prior RT (table 2). Dose prescription for re-irradiation was highly individual prior dose and respecting the patients' preferences after detailed discussion of risks and benefits.

\section{Treatment tolerance/toxicity}

Treatment was well tolerated despite comparatively long treatment times per session (set-up, position verification, treatment for carbon ions approx. $45 \mathrm{~min}$ ). There was no treatment break in any patient except one, a lady with Miur-Torre syndrome showing pronounced swelling of the irradiated area (floor of mouth/pharynx) necessitating elective tracheal tube insertion and treatment interruption for 3 fractions.

Treatment-related acute effects as assessed at completion of the radiation therapy course were generally mild with mucositis CTC ${ }^{\circ}$ III occurring in 9/103 pts (8.7\%); despite extensive treatment fields, no $>$ grade I xerostomia was found. Seventy-two patients (69.9\%) developed changes up to complete loss of taste gradually resolving until the first follow-up. Twenty-one patients (20.4\%) developed middle ear effusions/otitis requiring tympanostomy, 11 pts (10.7\%) otitis externa. Seventeen patients had a facial nerve palsy due to extensive surgical procedures or tumor compression, 3 patients showed improvement of cranial nerve palsies (palsy of the IIIrd, Vth, VIth cranial nerv) during the course of radiotherapy completely resolving at first follow-up in 2 patients. We observed radiation-induced erythema in 86 patients, (62 pts $\left.{ }^{\circ} \mathrm{II}, 25 \mathrm{pts}^{\circ} \mathrm{I}\right)$, one of them $\mathrm{CTC}^{\circ} \mathrm{III}$, small dry epitheliolyses were seen in 20 patients (19.4\%) mostly retro-/infraauricular area. Dysphagia of some degree was observed in about half of the patients, 3 patients were feeding tube (PEG) dependent prior to RT, 6 patients became PEG-dependent during therapy (dysphagia ${ }^{\circ} \mathrm{III}$ : $5.8 \%$ ). Radiation-induced side effects (loss of appetite/ taste, dysphagia) led to weight loss in 44 patients [2 - 11 $\mathrm{kg}]$ due to the complete loss of taste (table 3).

\section{Follow-up}

Acute toxicity rapidly resolved in most patients, at first follow-up, 12 patients (11.7\%) still complained of some difficulty swallowing $\left({ }^{\circ} \mathrm{I}\right), 3(2.9 \%)$ reported changes in their diet ( $\left.{ }^{\circ} \mathrm{II}\right)$ while one patient was still dependent on the feeding tube due to dental problems.

Xerostomia ${ }^{\circ} \mathrm{I}$ was reported by 41 patients (39.8\%) with symptoms gradually resolving. No skin reactions apart from one case erythema ${ }^{\circ} \mathrm{I}$ and hyperpigmentation I I (1 pt: $1.0 \%$ ) could be observed (table 3). One patient receiving re-irradiation developed an asymptomatic cystic necrosis of the intracranial tumor part. He is under close clinical and diagnostic follow-up.

\section{Outcome}

To date, only one patient receiving adjuvant radiation for R1 resection for ACC developed an in-field recurrence. This patient rapidly developed distant metastases (bone, lungs, liver) at the same time and is now undergoing chemotherapy.

Overall best response rate (CR and PR) in patients undergoing re-RT or RT for macroscopic/residual disease is $78.3 \%$ ( $47 / 60$ patients, SD in $15 / 60$ pts). To date, there were 8 complete remissions, one already at the first follow-up (table 4). In the patient group with 
Table 1 patient baseline characteristics

\begin{tabular}{llll}
\hline & Re-irradiation & visible residual tumor & R1/Pn+ resected tumors \\
\hline patient number & 16 & 60 & 43 \\
prior surgery & 5 & 26 & 43 \\
visible residual/no prior surgery & 15 & 60 & 0 \\
R1/Pn+ & 1 & 0 & 43 \\
recurrent tumors & 16 & 26 & 9 \\
re-irradiation & 16 & 15 & 1
\end{tabular}

Stages (TNM 7th edition 2010)

$\mathrm{T} 1$

$\mathrm{T} 2$

T3

$\mathrm{T} 4$

Tx

Not applicable

NO

N1

$\mathrm{N} 2 \mathrm{a}$

$\mathrm{N} 2 \mathrm{~b}$

$\mathrm{N} 2 \mathrm{C}$

\section{histology}

adenoid cystic carcinoma

mucoepidermoid carcinoma

acinic cell carcinoma

adenocarcinoma

squamous cell carcinoma

MSGT NOS

site

base of skull

intracranial extension

orbit

orbit/pterygopalatine fossa

petrous bone

nasal cavity

paranasal sinus

maxilla

palate

planum buccale

nasopharynx

oropharynx

external auditory canal

parotid gland

submandibular gland

sublingual gland

base of tongue

lacrimal gland
$6-901$

$1-1$

$16-7$

12

126

1

2

$12-17$

$2 \quad 5$

2 


\begin{tabular}{|c|c|c|c|c|}
\hline & re-irradiation & range & primary irradiation & range \\
\hline patient number & 16 & & 87 & \\
\hline \multicolumn{5}{|l|}{ median dose (GyE/Gy) } \\
\hline $\mathrm{C} 12$ & 44.7 & & 23.9 & $17.4-24.4$ \\
\hline IMRT & 48.8 & & 49.3 & $47-56.3$ \\
\hline total dose & 44.9 & $36.2-72.7$ & 73.2 & $69.9-75.3$ \\
\hline \multicolumn{5}{|l|}{$\mathrm{C} 12$} \\
\hline IMPT & 5 & & 17 & \\
\hline $\mathrm{SBO}$ & 10 & & 70 & \\
\hline \# of fractions & 15 & $8-20$ & 8 & $6-8$ \\
\hline \multicolumn{5}{|l|}{ IMRT } \\
\hline step\& shoot IMRT & 1 & & & 81 \\
\hline Tomotherapy & 0 & & & 6 \\
\hline \multicolumn{5}{|l|}{ treatment volumes $(\mathrm{ml})$} \\
\hline CTV1 & 55.2 & $9.2-178.7$ & 128.6 & $32.6-468.6$ \\
\hline CTV2 & 221.2 & $108.6-333.8$ & 368.0 & $100.2-1246.8$ \\
\hline \multicolumn{5}{|l|}{ prior RT } \\
\hline prior C12-irradiation & $6 \mathrm{pts}$ & & & \\
\hline median prior dose (GyE/Gy) & 70 & $50-72$ & & \\
\hline median re-RT dose (GyE/Gy) & 44.9 & $36.2-72.7$ & & \\
\hline median cumulative dose (GyE/Gy) & 113 & $59-133$ & & \\
\hline time interval (months) & 66 & $16-266$ & & \\
\hline
\end{tabular}

macroscopic tumor (incl. re-irradiation), three patients developed an in-field recurrence after initial partial response ( 2 patients receiving re-irradiation, 1 patient receiving primary $\mathrm{RT}$ ). Both of these patients were retreated only 19 and 16 months with 51 GyE and 36.2 GyE for acinic cell and mucoepidermoid carcinoma. One patient developed an out-of-field recurrence following re-irradiation, three patients had distant disease progressions.

Figures 1, 2, and 3 show a 27 year-old lady with large, partially-resected ACC (CTV1: $238.6 \mathrm{ml}$, CTV2: 572.2 $\mathrm{ml}$ ) before (Figure 1) and 6 months after radiotherapy (Figure 3) together with the corresponding carbon ion dose distribution created by a 3-field IMPT (Figure 2).

\section{Discussion}

Treatment was generally tolerated well and without unexpected acute toxicity. Transient alteration of taste, mild xerostomia, and dysphagia were most frequently reported. There was no grade IV or V acute toxicity. These findings are supported by other series using particle radiation $[9,11,14]$.

Despite the sometimes large treatment volumes, we have seen only 6 patients with ${ }^{\circ}$ III dysphagia (5.8\%).
Mucositis rates are higher than in our initial or the Japanese series, however, these mostly included tumors located at the base of skull $[9,15]$ and smaller target volumes [11]. Both cohorts $[9,11]$ also did not include $\mathrm{R} 1$-resected tumors. In view of treated sites in our patient cohort, occurrence of ${ }^{\circ} \mathrm{III}$ mucositis at roughly $10 \%$ is still very low especially considering the fact that the former parotid area was included in 14 out of 40 pts. Also, toxicity does not seem to be increased in the patients without macroscopic residues.

As especially ACCs tend to show perineural infiltration, an independent predictor of local control [4-6], therefore potentially involved neural tracts up to their entrance into the skull base need to be included as proposed by Garden et al [6]. Consequently, this brings higher dose close to the middle ear, therefore, the occurrence of middle ear effusions is not surprising. In all cases, these symptoms completely resolved at first follow-up and are therefore acceptable.

Although it is too early to assess treatment efficacy, response rates and extent of response in the patients with initially macroscopic residues are promising. With our updated results showing no difference in local control between partially resected or primarily irradiated 
Table 3 acute toxicity at completion of treatment and first follow-up

\begin{tabular}{|c|c|c|c|c|c|c|c|c|c|c|}
\hline & & re-irradiatio & & & macroscopic & residual & & microscopic & residual & \\
\hline & & prior to RT & end of RT & $1 \mathrm{st} f / \mathrm{u}$ & prior to $\mathrm{RT}$ & end of RT & $1 \mathrm{st} f / \mathrm{u}$ & prior to RT & end of RT & $1 \mathrm{st} f / \mathrm{u}$ \\
\hline mucositis & I & & 4 & & & 14 & 0 & & 16 & 1 \\
\hline & $\|$ & & 1 & & & 21 & 1 & & 18 & 0 \\
\hline & III & & 0 & & & 5 & 0 & & 4 & 0 \\
\hline dermatitis & । & & 2 & & & 33 & 1 & & 27 & 0 \\
\hline & $\|$ & & 2 & & & 10 & 0 & & 11 & 0 \\
\hline & III & & 0 & & & 1 & 0 & & & 0 \\
\hline epitheliolyses & yes & & 0 & & & 8 & 0 & & 12 & \\
\hline xerostomia & । & & 3 & & & 19 & 19 & & 21 & 22 \\
\hline & $\|$ & & & & & 1 & & & 0 & 0 \\
\hline dysphagia & I & & 0 & 1 & & 11 & 6 & & 10 & 5 \\
\hline & $\|$ & & & & & 6 & 0 & & 4 & 3 \\
\hline & III & & & & & 4 & 0 & & 2 & \\
\hline weight loss & yes & & 1 & & & 24 & 4 & & 19 & 5 \\
\hline kg & median & & 4 & & & 4 & & & 5 & \\
\hline & $\min$ & & & & & 2 & & & 2 & \\
\hline & $\max$ & & & & & 11 & & & 10 & \\
\hline feeding tube & & & 0 & & 3 & 4 & 4 & 4 & 5 & \\
\hline loss of taste & & & 2 & & & 37 & & & 33 & \\
\hline middle ear eff & ion & & 2 & 1 & & 11 & 2 & & 8 & 2 \\
\hline otitis & & & 1 & & & 4 & & & 6 & \\
\hline paralysis of fac & al nerve & 2 & 2 & & 5 & 5 & 5 & 10 & 10 & 9 \\
\hline ptosis & & 3 & 2 & & 3 & 1 & 1 & & & \\
\hline reduced jaw o & ening & 2 & 2 & & 8 & 8 & 3 & 12 & 12 & 5 \\
\hline xerophthalmia & & & & & 1 & 1 & & 1 & 1 & 1 \\
\hline conjunctivitis & & & 1 & 0 & & 6 & 0 & & 2 & 0 \\
\hline lymph edema & & & & & & & 2 & & & 2 \\
\hline
\end{tabular}

ACCs [16], the role of extensive surgical procedures in the treatment of MSGT hence needs to be reconsidered. With rapidly resolving treatment-related side-effects and very mild late effects [9], the application of extensive and very often mutilating surgical procedures needs to be questioned, especially since inclusion of surgical intervention pathways lead to larger target volumes.

Table 4 initial treatment response

\begin{tabular}{lll}
\hline & $\begin{array}{l}\text { re-RT } \\
(\mathbf{N}=\mathbf{1 6})\end{array}$ & $\begin{array}{l}\text { primary/R2 } \\
(\mathbf{N}=\mathbf{6 0})\end{array}$ \\
\hline CR & & 8 \\
PR & 9 & 30 \\
SD & 4 & 11 \\
dna & 1 & 0 \\
pending & 2 & 9 \\
lost to f/u & 0 & 2 \\
& & \\
CR: complete response & & \\
PR: partial response & & \\
SD: stable disease & & \\
dna: does not apply & & \\
\hline
\end{tabular}

Albeit longer follow-up is needed to assess late effects of re-irradiation with carbon ions, our patients did not experience any major acute radiation-induced toxicity. Observed side-effects were mild, with very fast responses (i.e. resolution of ocular ptosis) occurring even under therapy. It has been shown in various publications that re-irradiation can lead to long-term local control at least in a subset of patients [20-22]. However this is bought at the price of increased late effects with the second course of irradiation. Local control for the second course of irradiation is challenging and also dose-dependent, therefore particle therapy appears to be a logical treatment choice in re-irradiation delivering high doses to the target while sparing surrounding normal tissues to a higher extent than either FSRT or IMRT are able to. While we could - in a small patient number - show that re-irradiation with carbon ions is possible maintaining a low (acute) toxicity profile, late effects still need to be investigated. Two patients in our re-irradiation cohort developed in-field recurrences following re-irradiation, therefore further dose escalation may be explored in a controlled clinical trial setting. 


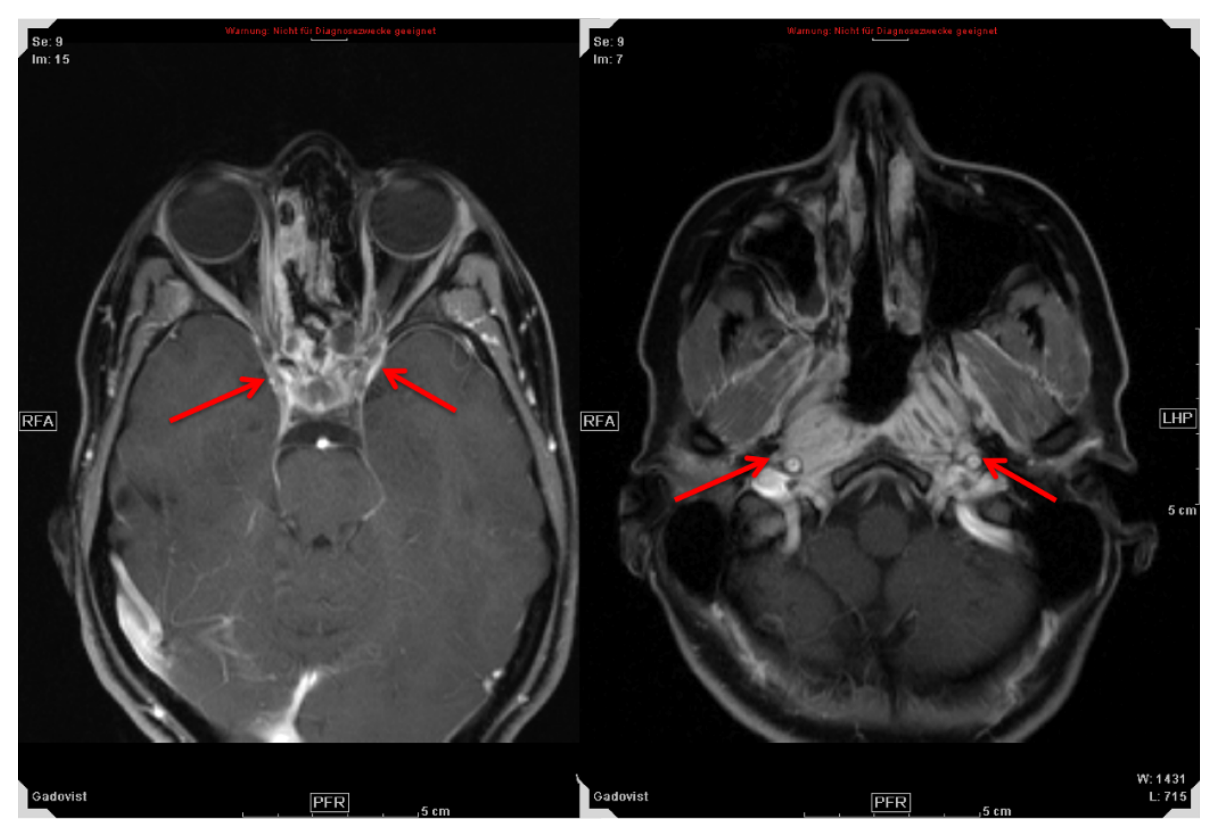

Figure 1 extensive adenoid cystic carcinoma in 27 year-old lady prior to RT.

As we hope long-term results with the slightly increased heavy-ion part in the treatment regimen will lead to further improved control rates, none of the local treatment regimen has yet had an impact on overall survival or distant metastasis-free survival in MSGT $[2,6,7,9]$. The use of concomitant chemotherapy or immunotherapy in squamous cell carcinoma of the head and neck $[23,24]$ has led to a significant improvement not only in local control but also in overall survival. Radiochemotherapy in treatment of MSGT however, has not evolved beyond the phase II-stage or retrospective analysis of very heterogeneous treatment regimen [25-27] so far.

Hence two open questions still remain: can we increase local control at acceptable rates of side-effects in adenoid cystic carcinoma and other malignant salivary gland tumors by increase of the carbon ion $\mathrm{RT}$ part? A prospective controlled trial is currently under way to address this issue [17]. The other question is whether patients with adenoid cystic carcinoma will profit from combined treatment with i.e. new substances such as EGFR-inhibitors, which will potentially not

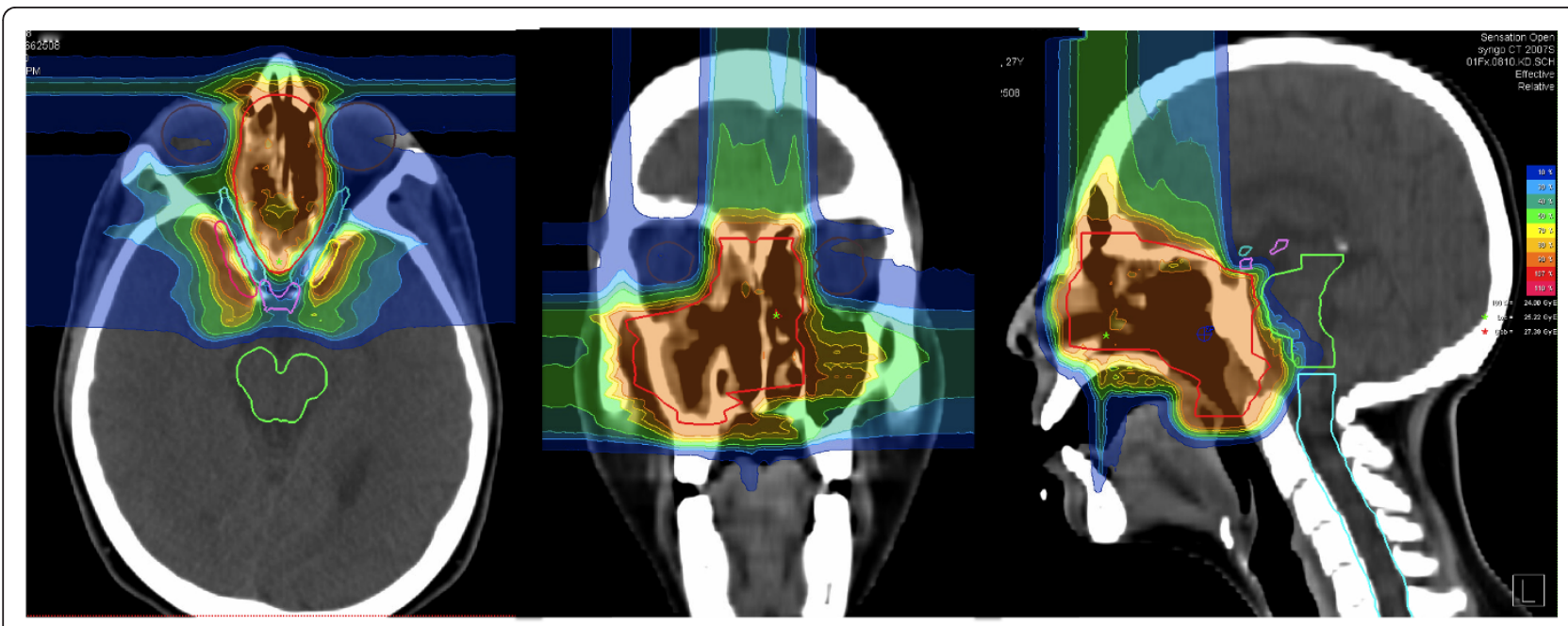

Figure 2 corresponding carbon ion dose distribution by a 3-field IMPT: 100\% corresponding to 24 GyE. 


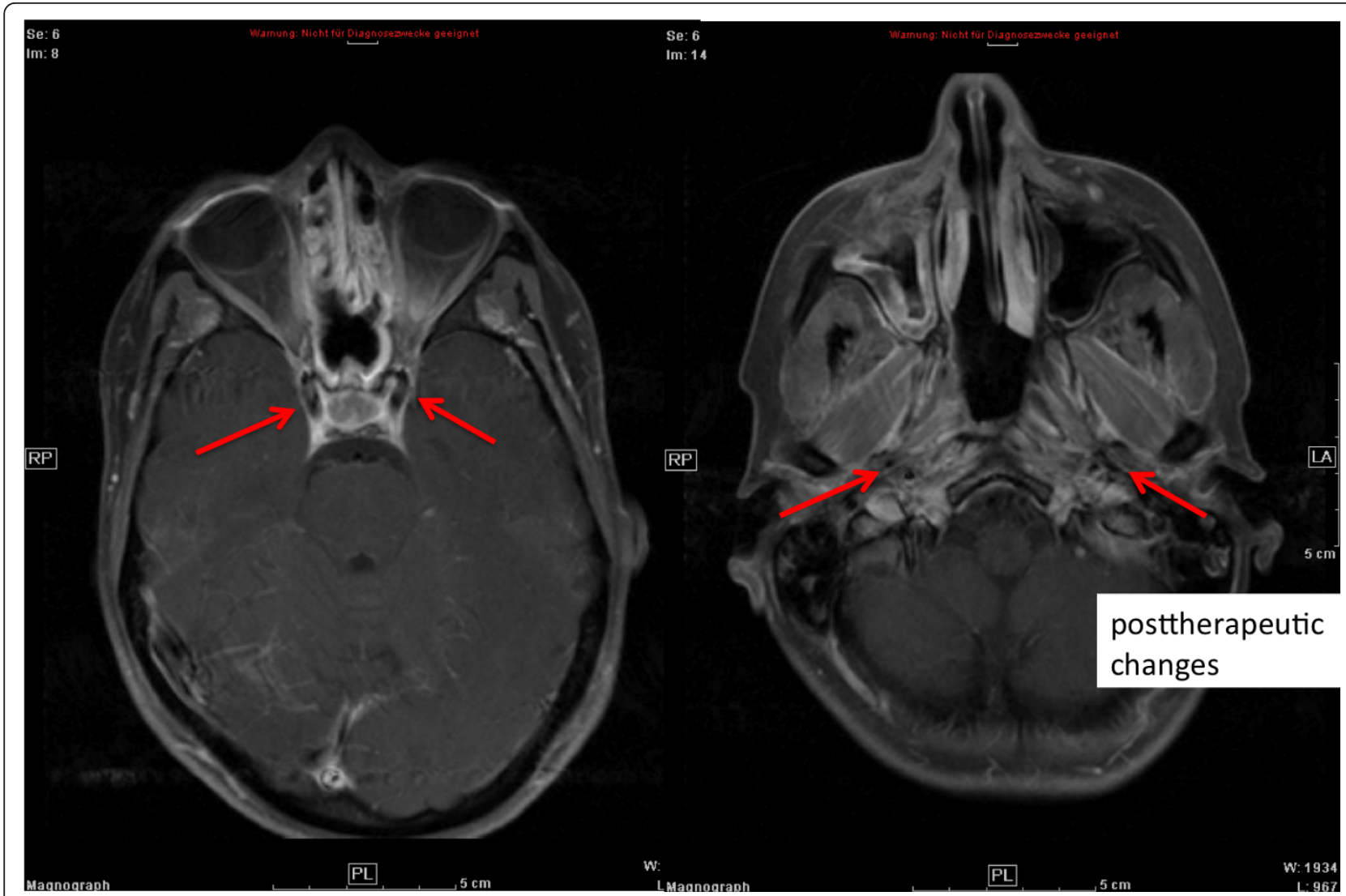

Figure 3 complete remission 6 months post combined RT (transversal contrast-enhanced MRI).

increase treatment-related side effects significantly $[23,28]$ in terms of local and distant control. This issue will also shortly be addressed in a prospective phase-II trial [29].

\section{Conclusion}

Achieving local control in MSGT remains challenging. IMRT with carbon ion boost has led to only mild acute side effects in R2-resected tumors of the skull base, toxicity does not seem to be increased in R1-resected tumors of this series. R2-resected patients showed promising treatment response, follow-up is yet too short though to assess long-term local control and potential late effects. Carbon ion therapy for re-irradiation has been shown to be feasible and without significant associated acute toxicity.

\section{Author details}

'Dept. Radiation Oncology, University of Heidelberg, INF 400, 69120 Heidelberg, Germany. ${ }^{2}$ Dept. of Medical Physics, Heidelberg Ion Beam Therapy Centre (HIT), INF 450, 69120 Heidelberg, Germany.

\section{Authors' contributions}

$A D J, A V N, K K H$, and MWM were responsible for treatment concepts and patient care, SE, ME for technical treatment planning and quality control, and $\mathrm{KKH}, \mathrm{JD}$ and MWM for conceptual design. All authors read and approved the final manuscript.

\section{Competing interests}

The authors declare that they have no competing interests.

Received: 21 September 2011 Accepted: 2 November 2011 Published: 2 November 2011

\section{References}

1. Spiro RH: Salivary neoplasms: overview of a 35-year experience with 2,807 patients. Head Neck Surg 1986, 8(3):177-84.

2. Chen AM, Granchi PJ, Garcia J, Bucci MK, Fu KK, Eisele DW: Local-regional recurrence after surgery without postoperative irradiation for carciomas of the major salivary glands: implications for adjuvant therapy. Int J Radiat Oncol Biol Phys 2007, 67:982-987.

3. Gurney TA, Eisele DW, Weinberg V, Shin E, Lee N: Adenoid cystic carcinoma of the major salivary glands treated with surgery and radiation. Laryngoscope 2005, 115(7):1278-82.

4. Mendenhall WM, Morris CG, Amdur RJ, Werning JW, Hinerman RW, Villaret DB: Radiotherapy alone or combined with surgery for adenoid cystic carcinoma of the head and neck. Head Neck 2004, 26(2):154-62.

5. Chen AM, Bucci MK, Weinberg V, Garcia J, Quivey JM, Schechter NR, Phillips TL, Fu KK, Eisele DW: Adenoid cystic carcinoma of the head and neck treated by surgery with or without postoperative radiation therapy: prognostic features of recurrence. Int I Radiat Oncol Biol Phys 2006, 66(1):152-9.

6. Garden AS, Weber RS, Ang KK, Morrison WH, Matre J, Peters L: Postoperative radiation therapy for malignant tumors of minor salivary glands. Outcome and patterns of failure. Cancer 1994, 73(10):2563-9.

7. Terhaard CHJ, Lubsen H, Van der Tweel I, Hilgers FJM, Eijkenboom WMH Marres HAM, Tjho-Heslinga RE, de Jong JM, Roodenburg JL, Dutch Head 
and Neck Oncology Cooperative Group: Salivary gland carcinoma: independent prognostic factors for locoregional control, distant metastases, and overall survival: results of the Dutch head and neck oncology cooperative group. Head Neck 2004, 26:681-92, discussion 692-3.

8. Terhaard CHJ, Lubsen H, Rasch CRN, Levendag PC, Kaanders HHAM, TjhoHeslinga RE, van Den Ende PL, Burlage F, Dutch Head and Neck Oncology Cooperative Group: The role of radiotherapy in the treatment of malignant salivary gland tumors. Int J Radiat Oncol Biol Phys 2005, 61:103-111.

9. Schulz-Ertner D, Nikoghosyan A, Didinger B, Munter M, Jakel O, Karger CP, Debus J: Therapy strategies for locally advanced adenoid cystic carcinomas using modern radiation therapy techniques. Cancer 2005, 104(2):338-44.

10. Douglas JG, Koh WJ, Austin-Seymour M, Laramore GE: Treatment of salivary gland neoplasms with fast neutron radiotherapy. Arch Otolaryngol Head Neck Surg 2003, 129(9):944-8.

11. Mizoe JE, Tsujii H, Kamada T, Matuoka Y, Tsuji H, Osaka Y, Hasegawa A, Yamamoto N, Ebihara S, Konno A, Organizing Committee for the Working Group for Head-And-Neck Cancer: Dose escalation study of carbon ion radiotherapy for locally advanced head-and-neck cancer. Int J Radiat Oncol Biol Phys 2004, 60(2):358-64.

12. Huber PE, Debus J, Latz D, Zierhut D, Bischof M, Wannenmacher M, Engenhart-Cabillic R: Radiotherapy for advanced adenoid cystic carcinoma: neutrons, photons or mixed beam? Radiother Oncol 2001, 59(2):161-7.

13. Münter MW, Schulz-Ertner D, Hof H, Nikoghosyan A, Jensen A, Nill S, Huber P, Debus J: Inverse planned stereotactic intensity modulated radiotherapy (IMRT) in the treatment of incompletely and completely resected adenoid cystic carcinomas of the head and neck: initial clinical results and toxicity of treatment. Radiat Oncol 2006, 1:17.

14. Pommier P, Liebsch NJ, Deschler DG, Lin DT, Mclntyre JF, Barker FG, Adams J, Am Lopes W, Varvares M, Loeffler JS, Chan AW: Proton beam radiation therapy for skull base adenoid cystic carcinoma. Arch Otolaryngol Head Neck Surg 2006, 132(11):1242-9.

15. Schulz-Ertner D, Nikoghosyan A, Jäkel O, Haberer T, Kraft G, Scholz M, Wannenmacher M, Debus J: Feasibility and toxicity of combined photon and carbon ion radiotherapy for locally advanced adenoid cystic carcinomas. Int J Radiat Oncol Biol Phys 2003, 56:391-398.

16. Münter M, Umathum V, Jensen AD, Nikoghosyan A, Hof $H$, Jaekel $O$, Debus J: Combination of intensity modulated radiation therapy (IMRT) and a heavy ion (C12) boost for subtotal resected or inoperable adenoid cystic carcinomas (ACCS) of the head and neck region. J Clin Oncol 2010, 28:e16010.

17. Jensen AD, Nikoghosyan A, Windemuth-Kieselbach C, Debus J, Münter MW: Combined treatment of malignant salivary gland tumours with intensitymodulated radiation therapy (IMRT) and carbon ions: COSMIC. BMC Cancer 2010, 10:546.

18. Haberer T, Becher W, Schardt D, Kraft G: Magnetic scanning system for heavy ion therapy. Nucl Instr Meth Phys Res 1993, 330:296-305.

19. Therasse P, Arbuck SG, Eisenhauer EA, Wanders J, Kaplan RA, Rubinstein L, Verweij J, Van Glabbeke M, van Oosterom AT, Christian MC, Gwyther SG: New guidelines to evaluate the response to treatment in solid tumors. J Natl Cancer Inst 2000, 92:205-216.

20. De Crevoisier R, Bourhis J, Domenge C, Wibault P, Koscielny S, Lusinchi A Mamelle $G$, Janot F, Julieron M, Leridant AM, Marandas P, Armand JP, Schwaab G, Luboinski B, Eschwege F: Full-dose reirradiation for unresectable head and neck carcinoma: experience at the GustaveRoussy Institute in a series of 169 patients. J Clin Oncol 1998 16:3556-3562.

21. Roh KW, Jang JJ, Kim MS, Sun DI, Kim BS, Jung SL, Kang JH, Yoo SC, Jang HS, Chung SM, Kim YS: Fractionated stereotactic radiotherapy as reirradiation for locally recurrent head and neck cancer. Int J Radiat Oncol Biol Phys 2009, 74:1348-1355.

22. Lee N, Chan K, Bekelman JE, Zhung J, Mechalakos J, Narayana A, Wolden S, Venkatraman ES, Pfister D, Kraus D, Shah J, Zelefsky MJ: Salvage reirradiation for recurrent head and neck cancer. Int J Radiat Oncol Biol Phys 2007, 68:731-740.

23. Bonner JA, Harari PM, Giralt J, Cohen RB, Jones CU, Sur RK, Raben D, Baselga J, Spencer SA, Zhu J, Youssoufian H, Rowinsky EK, Ang KK Radiotherapy plus cetuximab for locoregionally advanced head and neck cancer: 5-year survival data from a phase 3 randomised trial, and relation between cetuximab-induced rash and survival. Lancet Oncol 2010, 11:21-28

24. Pignon JP, le Maitre A, Maillard E, Bourhis J, MACH-NC Collaborative Group: Meta-analysis of chemotherapy in head and neck cancer (MACH-NC): an update. Int J Radiat Oncol Biol Phys 2007, 69:112-114.

25. Haddad RI, Posner MR, Busse PM, Norris CM, Goguen LA, Wirth LJ, Blinder R, Krane JF, Tishler RB: Chemoradiotherapy for adenoid cystic carcinoma: preliminary results of an organ sparing approach. Am J Clin Oncol 2006, 29:153-157.

26. Tanvetyanon T, Qin D, Padhya T, McCaffrey J, Zhu W, Boulware D, DeConti R, Trotti A: Outcomes of postoperative concurrent chemoradiotherapy for locally advanced major salivary gland carcinoma. Arch Otolaryngol Head Neck Surg 2009, 135:687-692.

27. Pederson A, Haraf D, Blair EA, Stenson KM, Witt ME, Vokes EE, Salama JK: Chemoreirradiation for recurrent salivary gland malignancies. Radiother Oncol 2010, 95:308-311.

28. Jensen AD, Krauss J, Weichert W, Debus J, Münter MW: Radiolmmunotherapy for adenoid cystic carcinoma: a single-institution series of combined treatment with cetuximab. Radiother Oncol 2010, 5:102.

29. Jensen AD, Nikoghosyan AV, Hinke A, Debus J, Münter MW: Combined treatment of adenoid cystic carcinoma with cetuximab and IMRT plus C12 heavy ion boost: ACCEPT [ACC, Erbitux ${ }^{\oplus}$ and particle therapy]. BMC Cancer 2011, 11:70.

\section{doi:10.1186/1748-717X-6-149}

Cite this article as: Jensen et al: Raster-scanned carbon ion therapy for malignant salivary gland tumors: acute toxicity and initial treatment response. Radiation Oncology 2011 6:149.

\section{Submit your next manuscript to BioMed Central and take full advantage of:}

- Convenient online submission

- Thorough peer review

- No space constraints or color figure charges

- Immediate publication on acceptance

- Inclusion in PubMed, CAS, Scopus and Google Scholar

- Research which is freely available for redistribution

Submit your manuscript at www.biomedcentral.com/submit
C) Biomed Central 